\title{
Cultura laboral mexicana: análisis desde la perspectiva de Octavio Paz en "Laberinto de la soledad"
}

Mexican labor culture: analysis from the perspective of Octavio Paz in "Laberinto de la soledad"

Nancy Marely Escobedo González ${ }^{1}$

\begin{abstract}
Resumen
El presente ensayo aborda la cultura laboral de forma general para posteriormente enfocarse a dicha cultura dentro de México, considerando los cambios que generaron la industrialización y el capitalismo en las costumbres y prácticas realizadas dentro de las áreas de trabajo. El análisis se realiza considerando la perspectiva que maneja Octavio Paz en su libro "Laberinto de la soledad", sobre los aspectos antes mencionados.
\end{abstract}

Palabras clave: Cultura laboral, México, trabajadores, capitalismo, prácticas laborales.

\begin{abstract}
This essay deals with labor culture in a general way to later focus on that culture within Mexico, considering the changes that industrialization and capitalism generated in the customs and practices carried out within the work areas. The analysis is made considering the perspective that Octavio Paz manages in his book "Laberinto de la soledad", on the aforementioned aspects.
\end{abstract}

Keywords: Work culture, Mexico, employees, capitalism, labor practices.

Maestría en Admınıstración por la Unıversıdad Autónoma de Cludad Juárez, Instituto de Ciencias Sociales y Administración. Av. Universidad y Heroico Colegio Militar Ciudad Juárez, Chih.

Correos electrónicos: marely_30_916@hotmail.com,nancy.escobedo@uacj.mx 


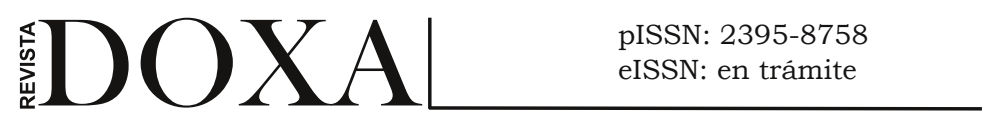

Introducción

Como punto inicial de este documento se abordará la cultura laboral para una mayor comprensión del término, todo lo que éste implica y la forma en que será utilizando dentro del ensayo, posteriormente se delimita a un solo espacio geográfico, México, ya descrita la cultura laboral.

La pregunta es ¿cómo es la cultura laboral en México?, para explicar esto fue necesario revisar algunos aspectos importantes a través de la historia de este país como son: la industrialización y el capitalismo, dando paso posteriormente, a algunas de las principales prácticas y costumbres que se tienen dentro de las áreas laborales en los distintos estados y ciudades de México.

\section{Desarrollo}

El término cultura laboral es explicado por Green (2005) como, un proceso humano separado pero íntimamente relacionado con las estructuras y requisitos de la organización. Una empresa u organización está formada por personas, entre otros muchos aspectos, y cada una de esas personas posee un bagaje cultural propio que ha ido adquiriendo a través del tiempo con sus experiencias, tradiciones, costumbres, etc.

Cuando estas personas comienzan a formar parte de la organización no pueden dejar de lado ese bagaje, pero sí adquieren una nueva cultura, aquella propia de la organización. Se adaptan a las políticas, prácticas y costumbres de la misma, formando parte de esta nueva cultura que funge como un "marco referencial que permite guiarse con pautas de comportamiento e interpretación de la realidad específica que significa formar parte. Permite que sus integrantes sepan cómo se hacen las cosas ahí, les da la posibilidad de compartir los significados que dan cohesión al grupo humano" (Terán y Lorenzo, 2011).

Dicha cultura es distinta en cada espacio geográfico y en cada contexto, puede variar incluso en cada organización ya que tienen normas y prácticas distintas, además de patrones culturales provenientes de sus lugares de origen. En esta ocasión se dará énfasis a México desde la perspectiva que comparte Octavio Paz en su libro Laberinto de la soledad.

Mendoza (2010) indica que la cultura del trabajador en México ha sido 
pISSN: 2395-8758

eISSN: en trámite

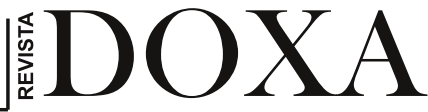

estudiada desde tiempo atrás y se ha caracterizado de diversas maneras, siempre con la inquietud de explicar, tanto las motivaciones, las actitudes, las expectativas, así como el desempeño.

Distintos momentos y acontecimientos durante la historia de México han ido marcando esta cultura que caracteriza a las tan variadas áreas laborales a lo largo de todo el país; considerando, claro está, que la diversidad cultural que posee México es muy rica y distinta en cada uno de sus espacios y contextos, permeando la cultura laboral, pero se pueden rescatar algunos aspectos generales de los cuales se habla en este ensayo.

Uno de los momentos que marca fuertemente a la cultura laboral mexicana es “el capitalismo que pasó gradualmente de las formas primitivas de acumulación a otras cada vez más complejas, hasta desembocar en la época de capital financiero y el imperialismo mundial.

Esta expansión imperialista unificó al planeta: captó todas las riquezas, aun las más escondidas y las arrojó al torrente de la circulación mundial convertidas en mercancías; universalizó el trabajo humano" (Paz, 1992).

Smith indica que hay dos circunstancias con las cuales se puede aumentar el consumo per cápita: incrementando la productividad de los trabajadores e incrementando la cantidad de trabajadores productivos, pero destaca que tiene mayor relevancia el incremento de la productividad de los trabajadores ya que es posible que, a pesar de que toda la población con capacidad productiva se ubique en un trabajo productivo, la producción no sea suficiente para cubrir la demanda de la sociedad.

Sin embargo lograr que los trabajadores sean productivos implica una serie de aspectos a considerar que van desde un lugar de trabajo adecuado hasta responsabilidades y pagos justos por su desempeño.

Con todos estos cambios en el ámbito laboral, menciona Paz (1992) que, los obreros se volvieron como hijos de las máquinas ya que el obrero moderno carecía de individualidad, siendo esa la primera y más grave mutilación que sufre el hombre al convertirse en asalariado industrial.

El capitalismo llega a despojarlo de su naturaleza humana, puesto que reducía todo su ser a tan sólo fuerza de trabajo, transformándolo por este hecho en un objeto. Pierde, bruscamente y por razón de su mismo estado social, toda relación humana y concreta con el mundo: ni son suyos los útiles que emplea, ni es suyo el fruto de su esfuerzo, ni siquiera lo ve.

Como es el caso de la industria automotriz en la cual lo operadores son 


\section{DOXA}

pISSN: 2395-8758

eISSN: en trámite

sometidos a jornadas laborales rutinarias, con pocas actividades o quizá sólo una, muy específica, que repite durante todo su turno, en la cual utiliza una serie de herramientas y materiales con los cuales crea un producto; al juntar cada uno de estos productos que los operadores realizan día con día, se crea un automóvil, en algunos casos automóviles de lujo, altamente costosos, y el operador con su esfuerzo ayudó a hacerlo posible más sin embargo no puede poseerlo.

Es por esto que Paz (1992) considera que las sociedades industriales se empeñan en transformar las diferencias cualitativas, es decir: humanas, en uniformidades cuantitativas. Los métodos de la producción en masa (confección de piezas sueltas que luego se unen) terminan aplicándose también a la moral, al arte y a los sentimientos de todas aquellas personas que conforman estas sociedades.

\section{Conclusión}

En suma, aunque contamos con una industria, todavía somos esencialmente, un país productor de materias primas. $\mathrm{Y}$ esto significa dependencia de las oscilaciones del mercado mundial, en lo exterior; y en lo interior pobreza, diferencias atroces entre la vida de los ricos y los desposeídos, desequilibrio.

Toda esta situación que ha traído la industria al mundo laboral y a la sociedad en México ha cambiado el ritmo de vida y algunas de las costumbres o acciones del día a día de los mexicanos. Una vida acelerada que para muchos consiste en levantarse incluso antes de salir el sol para dirigirse a sus espacios laborales, pasar ahí gran parte del día realizando las mismas actividades para regresar por la tarde a casa, convivir un momento con la familia (en el caso de quienes cuentan con una) y acostarse a descansar para repetir la misma rutina a la mañana siguiente.

Es por esto que buscan alguna forma salir de la monotonía con cualquier acción que sea distinta a su normalidad y proporcione un poco de alegría a sus vidas, para Paz (1992) cualquier pretexto es bueno para interrumpir la marcha del tiempo y celebrar con festejos y ceremonias.

Nuestro calendario está poblado de fiestas ya que a través de la fiesta las personas pueden burlarse de sus Dioses, de sus principios y de sus leyes, pareciera que todo se permite: desaparecen las jerarquías habituales, las distinciones sociales, los sexos, las clases, los gremios. 


\section{Referencias}

Failache, C. (2016). La Teoría del Desarrollo Económico de Adam Smith. Facultad de Ciencias Económicas y de Administración, noviembre 2016.

Green, T. (2005). Work culture and discrimination. California Law Review, 93(3), pp. 623-684. Recuperado de https://scholarship.law.berkeley.edu/cgi/viewcontent.cgi?referer= https:// scholar.google.com.mx/\&httpsredir $=1 \&$ article $=1297 \&$ con text=californialawreview

Maldonado, M. (2010). Mexicanos. Cultura mexicana y posmodernidad. Revista del Instituto de Ciencias Jurídicas, A.C., 25, pp.236-246.

Mendoza, J. (2010). Permanencia y evolución de la cultura laboral en México. El marco de referencia o modelo mental de trabajadores en organizaciones mexicanas. Innovaciones de negocios, 7(1), pp. 105-137.

Paz, O. (1992). Laberintos de la soledad. México, Fondo de Cultura Económica.

Terán, O. y Lorenzo, J. (2011). Influencia de la cultura organizacional en el desempeño laboral y la productividad de los trabajadores administrativos en instituciones de educación superior. Omnia, 17(1), pp.96-110. Recuperado de http://www.redalyc.org/pdf/737/73718406007.pdf 